\title{
Radiation Safety Awareness among patients and Radiographers in three Hospitals in Port Harcourt
}

\author{
Margaret A. Briggs-Kamara ${ }^{1}$, Polycarp C. Okoye ${ }^{2}$ and Valentine B. Omubo-Pepple ${ }^{3}$ \\ ${ }^{1}$ Department of Pure and Applied Physics, Veritas University Abuja, Obehie Campus, P.M.B. \\ 7084, Aba, Abia State, Nigeria \\ ${ }^{2}$ Department of Physics, University of Port Harcourt, P.M.B. 5323, Port Harcourt, Nigeria. \\ ${ }^{3}$ Department of Physics, Rivers State University of Science and Technology, Post Code \\ 500001, Port Harcourt, Nigeria.
}

\section{ABSTRACT}

People become nervous and worried whenever they are exposed to X-rays or similar forms of radiation. Such reactions may be attributed to ignorance, hearsay or actual knowledge of the harmful effects associated with these forms of radiation. To ascertain the true position a Radiation Safety Awareness survey was conducted among patients who receive X-ray irradiation at three Hospitals in Port Harcourt, Rivers State. The study employed the use of a carefully thought-out questionnaire administered to one hundred and fifty (150) patients and radiographers at the selected hospitals. Seventy-five of eighty $(93.8 \%)$ of the radiographers, and sixty of seventy $(85.7 \%)$ of patients responded. Of these $44(58.7 \%)$ of the radiographers reported that they were aware of the dangers of ionizing radiation, while $52(86.7 \%)$ of the patients expressed ignorance. We have shown that the patients' awareness of the dangers of ionizing radiation is very poor while level awareness by the radiographers is unacceptable. In conclusion, concerted effort is to be made by all concerned for a successful healthcare delivery.

Keywords: Patients, Radiation Safety Awareness, Radiographers, X-ray exposure.

\section{INTRODUCTION}

The use $\mathrm{X}$-rays in imaging modalities such as Computed Tomography (CT scans) and mammography to diagnose injury and illness is on the increase in modern medicine. The biological effects of ionizing radiations are of concern here as evidence shows that medical uses of radiations have harmful effects (Hendee and Edwards, 1996). According to the neuroradiologist Mark Pfleger (http://healthyoutlook.dephealth.com, 2011) patients and the community need to understand the safe use of radiation, and to become more active participants in their own healthcare. Quinn et al. (1997), Bushberg et al. (2003) and Kiguli-Malwandde et al. (2006) report that radiographers and clientele are not very awareness of radiation doses, and that there is a lack of communication between radiographers and patients relating to radiation and its possible effects.

$X$-ray utilization in human medicine leads to exposure of the patient and the radiographer. Although the radiation dose is low in diagnostic examinations, attention is usually given in order to minimize unnecessary exposure for members of the public and occupational workers. Exposure to ionizing radiation cannot be avoided in medical imaging facilities.
Radiation exposure over a long period of time (years) produces stochastic effects (NCRPM, 1980). There is no threshold level of radiation exposure below which it could be said with certainty that cancer or genetic effects will not occur. Doubling the radiation dose doubles the probability that a cancer or genetic effect would occur (Kondo, 1993).

The steps needed to prevent accidental exposures to any part of the body include adequate training of personnel, enlightenment of non-radiation workers in the vicinity of radiation sources (Belyakov et al., 2001), monitoring and control of radiation exposures, putting up warning signs, and proper disposal of radioactive waste.

Questions arise in the daily utilization of radiation facilities. Questions like: Are these radiation emitting facilities safe? Are patients under-exposed, probably leading to repeat of the exposure or over-exposed in the course of getting good results? Are they fully aware of the radiation dose and the risk associated with radiological procedures? Are they aware that no radiation worker should be below 18 years of age in keeping with established regulation (ICPR, 1992)? Are they also aware of the 10-day and 28-day rules that apply to females of child-bearing 
age/pregnant/breast-feeding mothers to prevent exposure of foetus and bodily contamination with radiation (Philip, 1991)? The authors had observed that practices in the hospitals being investigated did not take into cognizance that although the quantity of radiation is low in diagnostic examinations there is a need to minimize unnecessary exposure for both radiographer and patient.

\section{MATERIALS AND METHODS}

The questionnaire method of research was used. One hundred and fifty (150) questionnaires were administered to eighty (80) radiographers and seventy (70) patients at three Hospitals. Seventy-five (75) radiographers and sixty (60) patients completed and returned theirs. The questionnaire was designed to field questions in three parts: A, B and C.

Part A fielded questions on respondents' personal information and covered sex, age, educational level, and the respondent's knowledge of the effects of radiation.

Part B was exclusively for the radiographers. The questions asked included qualifications, frequency of and reasons for repeated radiologic examinations on patients, and alerting patients on the dangers associated with exposures, application of established safety rules.

Part C was for the patients. The questions asked include frequency of exposure to radiation, whether exposure was undertaken on recommendation of a medical practitioner or on self-request, and if any protective/shielding devices were used during exposures.

Data from the responses to the questionnaires were analyzed using the chi-square test (Pagano, 1994). The expected frequency depended on the hypothesis being tested. For the radiation workers, it was expected that at least $50 \%$ of the workers would be aware of the benefits and harm of ionizing radiation. This was the null hypothesis. The alternative hypothesis was that less than $50 \%$ of the workers were aware of the benefits and dangers of ionizing radiation. For patients the percentage used was $40 \%$ because the authors expect the radiographer to be better informed than the patient.

\section{RESULTS}

Responses from the questionnaires reveal that fortythree $(57.3 \%)$ of the radiographers were male while thirty-two (42.7\%) were female. Twenty-five (41.7\%) of the patients were male while 35 (58.3\%) were female. The mean age for the radiographers was 38 years and for the patients it was 37 years. Forty-four $(58.7 \%)$ of the radiographers responded that they were aware of the benefits/hazards of radiation while $31(41.3 \%)$ claimed ignorance. Eight $(13.0 \%)$ of the patients said they were aware while $52(86.7 \%)$ said they were not aware.

The spread in levels of educational qualification for the respondents is displayed on Figure 1. The frequencies at which patients are given explanations of procedure before exposures are shown on Figure 2 , while Figure 3 shows the frequency of patients' repeated exposures to radiation. Figure 4 shows the responses of patients on use of protective devices during exposures and Figure 5 shows the frequency of radiographer request for patients' consent before examination. The origin of radiographic requests is shown on Figure 6 . The chi-square results for the respondents are shown on Table 1.

Table 1: Chi-square results for the respondents

\begin{tabular}{|c|c|c|c|c|c|c|c|c|}
\hline $\begin{array}{l}\text { Level of } \\
\text { awareness }\end{array}$ & $\begin{array}{l}\begin{array}{l}\text { Observed } \\
\text { frequencies }\end{array} \\
F_{o}\end{array}$ & $\begin{array}{l}\text { Binomial } \\
\text { probability of } \\
\text { possible } \\
\text { outcome, } \\
B_{p}\end{array}$ & $\begin{array}{l}\text { Expected } \\
\text { frequencies, } \\
F_{e}=F_{o} B_{p}\end{array}$ & $\chi^{2}=\frac{\left(F_{o}-F_{e}\right)^{2}}{F_{e}}$ & & & & \\
\hline & 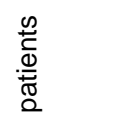 & $\begin{array}{l}\frac{\pi}{0} \\
\frac{0}{0} \\
\frac{\pi}{0} \\
\frac{1}{2}\end{array}$ & 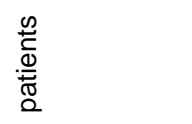 & 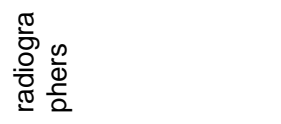 & 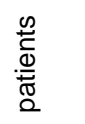 & 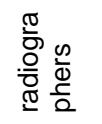 & 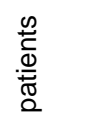 & 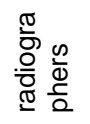 \\
\hline Very well & 3 & 32 & 0.216 & 0.125 & 12.96 & 9.375 & 7.65 & 54.60 \\
\hline Well & 9 & 6 & 0.432 & 0.375 & 25.92 & 28.125 & 11.05 & 17.41 \\
\hline $\begin{array}{l}\text { Little } \\
\text { awareness }\end{array}$ & 19 & 6 & 0.288 & 0.375 & 17.28 & 28.125 & 0.17 & 17.41 \\
\hline $\begin{array}{l}\text { No } \\
\text { awareness }\end{array}$ & 29 & 31 & 0.064 & 0.125 & 3.84 & 9.375 & 164.85 & 49.88 \\
\hline TOTAL & 60 & 75 & 1.000 & 1.000 & 60 & 75 & 183.72 & 139.30 \\
\hline
\end{tabular}


Am. J. Sci. Ind. Res., 2013, 4(1): 83-88

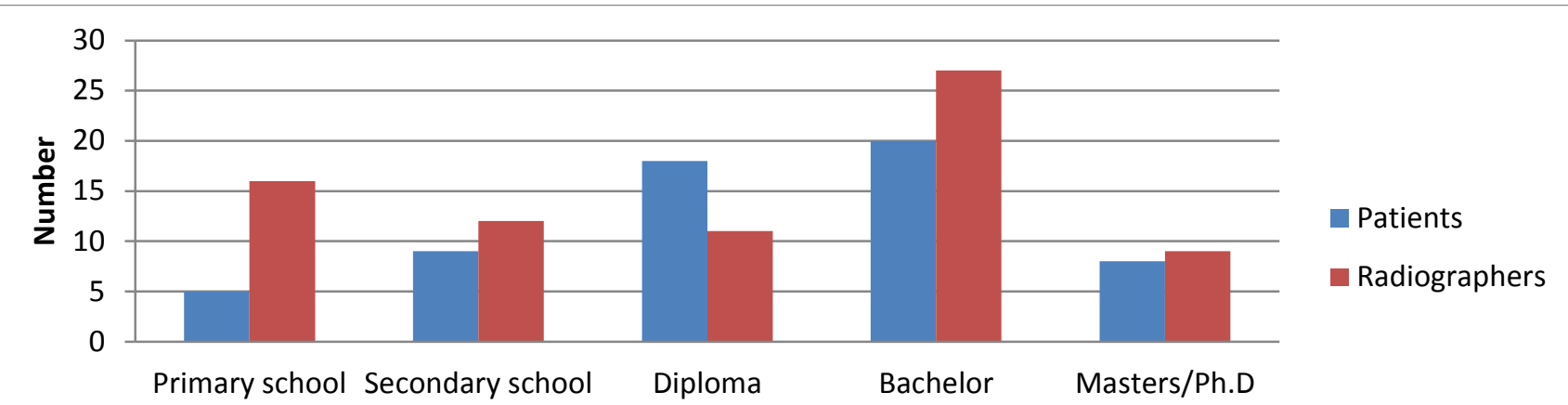

Fig 1: Educational Qualification of respondents

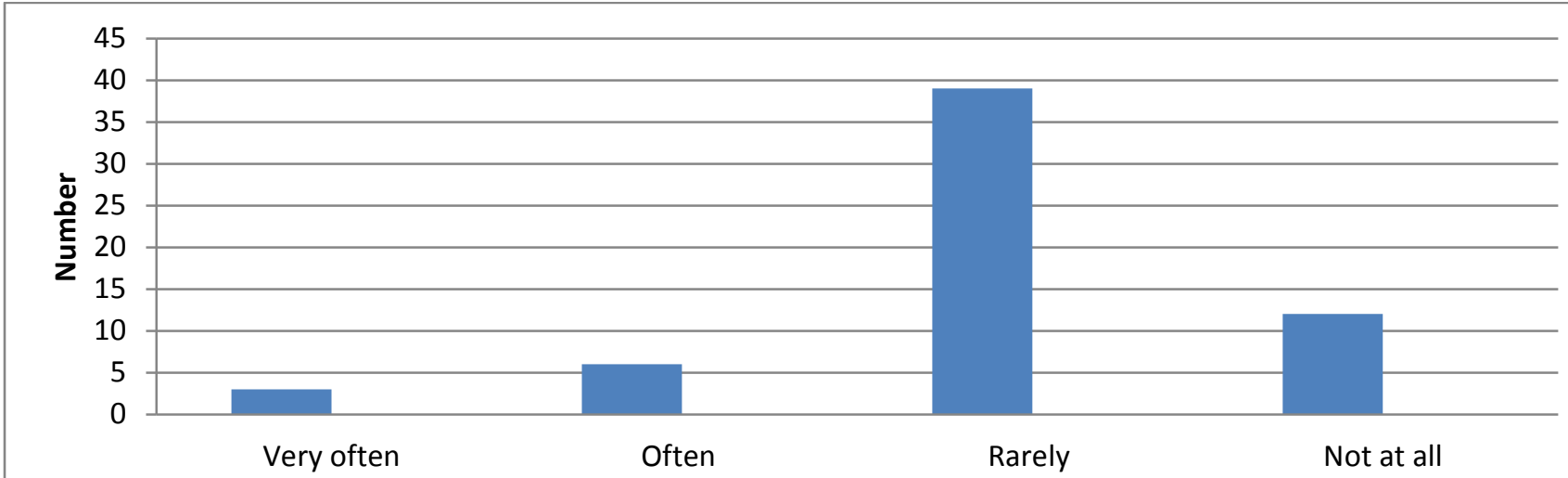

Fig 2: Frequency at which patients were given explanation of procedures before exposures

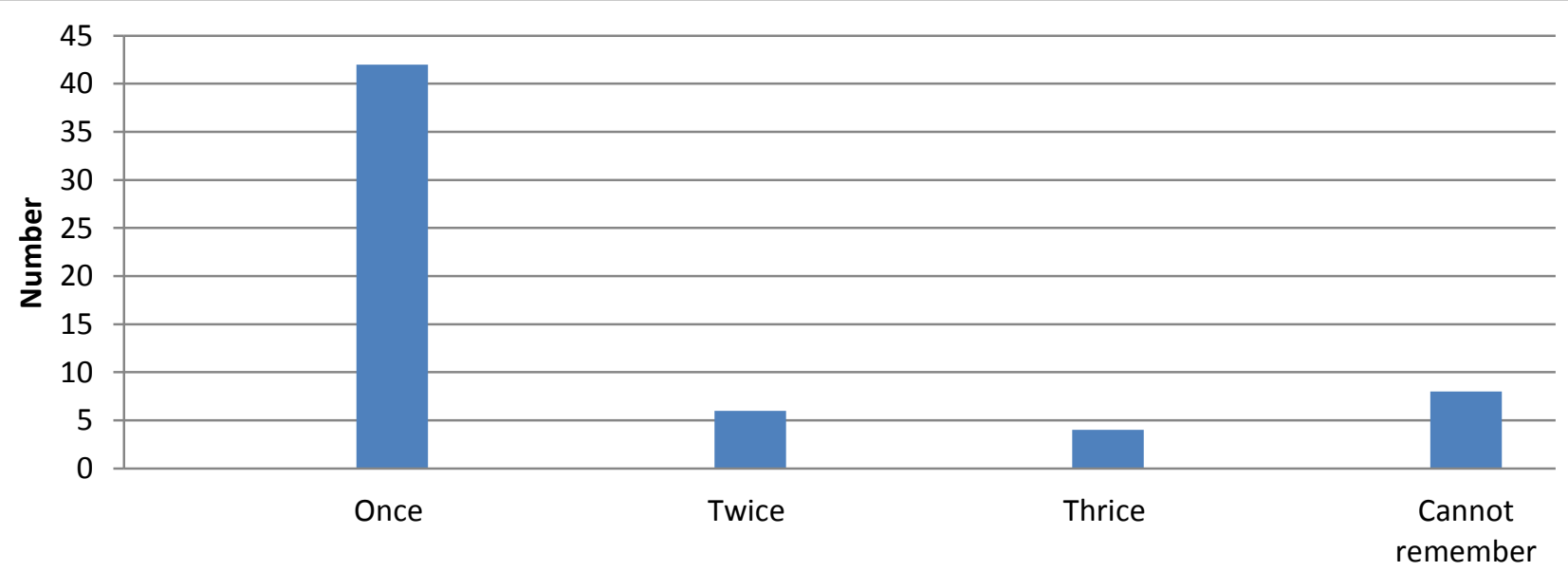

Fig 3: Frequency of patients' repeated exposure to radiation 
Am. J. Sci. Ind. Res., 2013, 4(1): 83-88

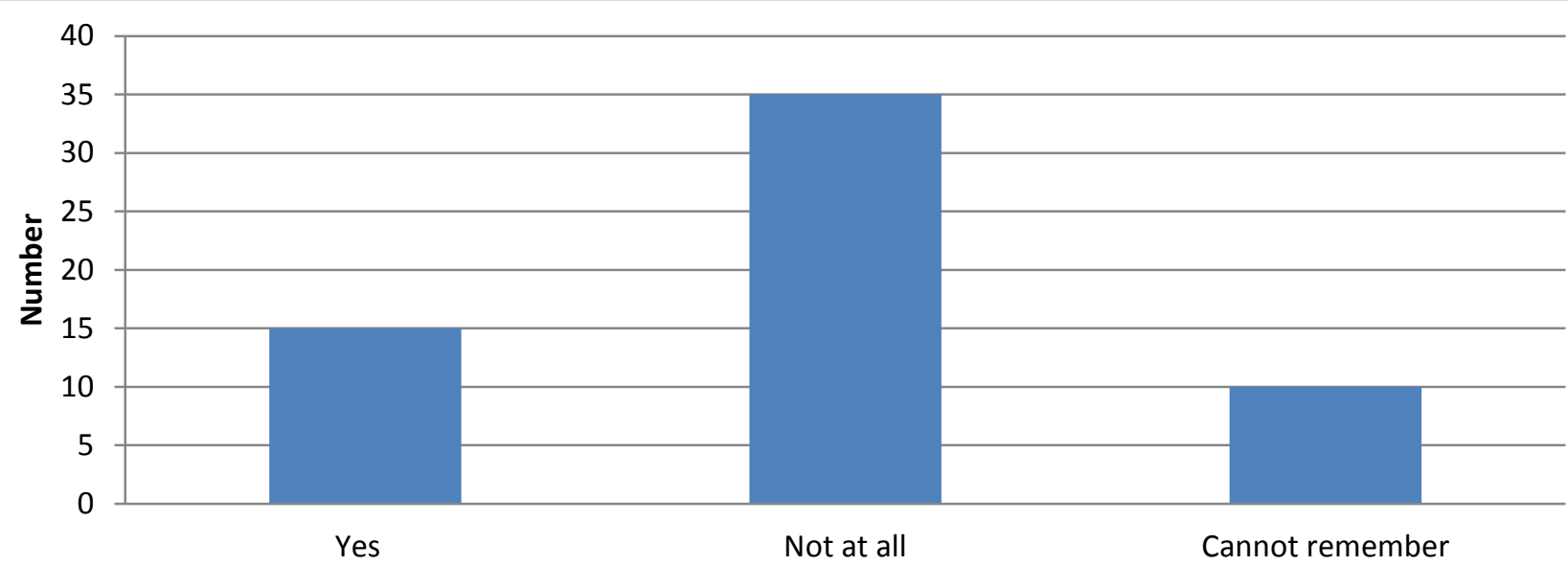

Fig 4: Responses of patients on use of protective devices during their exposures

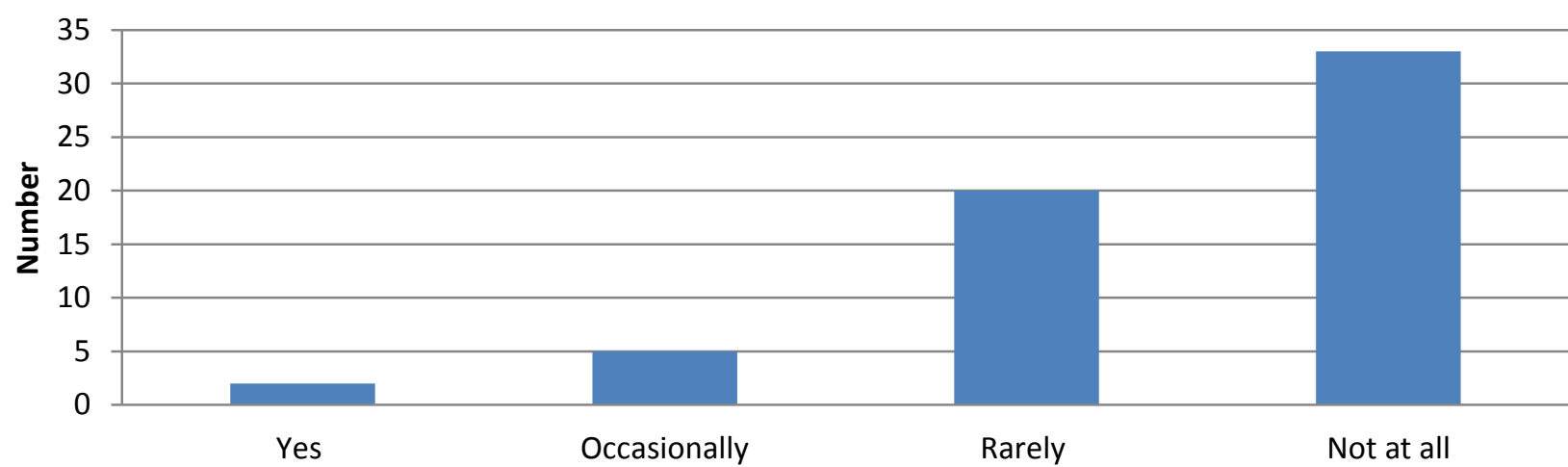

Fig 5: Frequency of radiographer request for patients' consent before examination

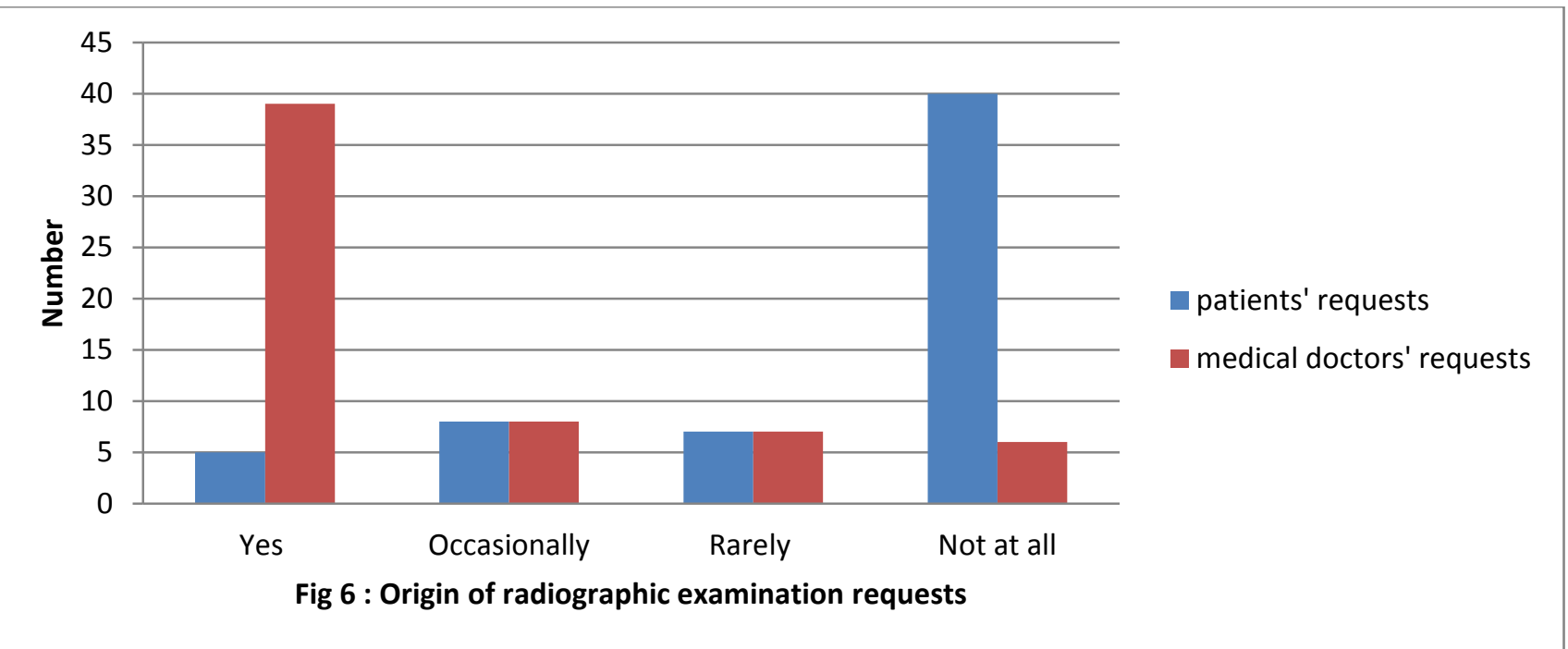




\section{DISCUSSION}

Hospitals that have radiotherapy and diagnostic radiological equipment are expected to take measures that ensure safety of both personnel and patients. In this study no radiation worker was below 18 years of age. This is in keeping with Established Regulation that nobody below the age of 18 is permitted to work in radiation zones( ICRP, 1992). The percentage $(86.7 \%)$ of patients who did not know that $\mathrm{X}$-rays were dangerous was very high and unacceptable. This placed a big responsibility on the radiation workers to explain and protect them.

A good number of patients had formal education though not aware of the dangers of ionizing radiation. This meant that besides being able to respond without difficulty to the questions on the questionnaire, it would not be so difficult for them to understand what radiation was if explanation was offered.

More than $60 \%$ of the patients reported that the radiation workers did not explain procedures before carrying out exposures on them. Radiation workers should as a matter of routine explain every procedure to patients before carrying it out. This would help allay fears on the part of patients and get full cooperation which would further help to reduce repeated investigations by way of not keeping still or failure to carry out instructions. Approximately $30 \%$ of the patients reported that they have had to repeat exposures due to reasons ranging from poor processing, loss or technical faults. Whatever the reasons, repeat exposures should not be encouraged because of the cumulative effects on the patients. It is desirable to reduce the number of repeated exposures and this could be effectively achieved if the X-ray machines are regularly inspected for optimal performance and if patients are educated on the need for careful handling of the radiographs. When these two aspects are under control, request for repeats as a way of confirming previous results might not be necessary as the radiographs would be clear and legible hence reducing risks.

Half of the patients, who remembered, reported that protective devices were used on them during exposures. This is grossly inadequate and unacceptable. Protective devices must always be used. Most $(88.3 \%)$ of the patients reported that the radiation workers did not seek their consent before exposing them to the radiation. Besides being a fundamental human right, patients need to become active participants in the whole process in order to keep radiation exposure to a minimum. It was encouraging to observe that majority $(85.7 \%)$ of the exposures were requested for by the Physician although there were a few cases (14.3\%) of selfrequests: an action which should be discouraged.

From Table 1, the calculated chi-square values of 183.72 and 139.30 fall far outside the acceptable region; hence the null hypotheses were rejected. Therefore, less than $50 \%$ of the radiographers and less than $40 \%$ of the patients were aware of the dangers of ionizing radiation. This was a cause for concern considering the number of patients exposed to ionizing radiation and the attendant risk associated with it.

\section{CONCLUSION}

There is radiation all around us and we need to be aware of the various sources, when to be concerned and how to protect ourselves from harmful exposure. Part of the responsibility for protecting people and the environment rests with the Government, but individuals have responsibilities too. Those working in radiation departments \{Radiographers, Radiologist and Technicians\} should also as a matter of urgent importance undergo trainings/ refresher courses in radiation.

Hospital Managements should design programmes which would emphasize patient education like introductory talks every morning before work begins. Information posters should be displayed throughout the hospital, and brochures that explain safety procedures and common concerns should be made available to all patients. There is also a need for more monitoring of these facilities by the Regulatory bodies.

\section{ACKNOWLEDGEMENT}

The authors are very grateful to staff members of the Radiologic Departments of the University of Port Harcourt Teaching Hospital (UPTH), Braithwaite Memorial Specialist Hospital (BMSH) and Rivon Clinic for their cooperation during data collection for this work. 


\section{REFERENCES}

Belyakov, O. V., Malcolmson, A. M., Folkard, M., Prise, K. M., and Michael, B. D. (2001). Direct evidence for a bystander effect of ionizing radiation in primary fibroblasts. Brit J Cancer 84: 674-679.

Bushberg, J. T., Selbert, J. A., and Leidholdt, M. E. (2003). Principles of Radiological Physics, Churchill and Livingstone, Philadelphia, 340-358.

Hendee, W. R. and Edwards, F. M. (1996). Health Effects of Exposure to Low-Level Radiation, Institute of Physics Publishing, Bristol, 420.

ICRP (1992). Recommendations of the International Commission on Radiological Protection, lonizing Radiation Fact Sheet Series No.4, ICRP Publication 40, Annals of the ICRP, 60-69.

Kiguli-Malwadde, E., Ddungu Matovu, P., Kawooya, M. G., and Byanyima, R. K. (2006). Radiation Safety Awareness among Radiation Workers and Clientele at Mulago Hospital, Kampala, Uganda. East and Central African Journal of Surgery 11(1): 49-51.
Kondo, S. (1993). Health Effects of Low-Level Radiation, Kinki University Press, Osaka, Japan, 50.

Mark Pfleger (2011)

http://healthyoutlook.dcphealth.com/summer2011/106-radiation-safety-awareness (assessed 20Dec-12)

NCRPM (1980). Influence of Dose and its Distribution in Time on Dose-Relationships for Low-LET Radiation, Report \#64 and \#70.

Pagano, R. R. (1994). Understanding Statistics in the Behavoural Sciences, $4^{\text {th }}$ Edition, West Publishing Company, Minneapolis/St. Paul, 452.

Philip, W. B. (1999). Radiographic positions and Radiologic procedures, $7^{\text {th }}$ Edition, Mosby-year Book, incorporated, Chicago, 25.

Quinn, A.D., Taylor, C. G., Sabharwal, T., and Sikdar, T. (1997). Radiation protection awareness in nonradiologists. The British Journal of Radialogy 70: $102-$ 106. 